\title{
So Close to Home
}

\section{Matthew Naqvi}

The businessman drives slow

down the main road.

Women of all ages, shapes and sizes

line up against the wall.

He spots a buxom blonde

calls her over to the car.

She jumps into the car

and they drive to the park.

She unzips his jeans

and fondles his penis.

She sucks on it

deeper and deeper each time.

He pulls her head closer

till her nose presses against his pubes.

Laughter bursts from his mouth as semen fills hers. 
He pulls up his jeans,

hands over a twenty.

He heads back home

to his wife and kids. 